\title{
Schistosomiasis mansoni and viral $B$ hepatitis in woodchucks
}

\author{
Zilton A. Andrade ${ }^{1, *}$, Pascale Berthillon ${ }^{2}$, Raimundo Paraná ${ }^{3}$, Jean-Alexis Grimaud ${ }^{2}$, Christian Trépo ${ }^{2}$ \\ ${ }^{1}$ Laboratory of Experimental Pathology, Gonçalo Moniz Research Center (FIOCRUZ), Salvador, Bahia, Brazil \\ ${ }^{2}$ INSERM Unité 271, Lyon, France \\ ${ }^{3}$ Department of Gastroenterology, University of Bahia Faculty of Medicine, Salvador, Bahia, Brazil
}

Background/Aims: An interaction between human schistosomiasis and viral hepatitis $B$ has often been suggested, but never established. The experimental investigation has been hampered by the lack of a suitable model. Only woodchucks are susceptible to both Schistosoma mansoni and a B-like hepatitis virus (WHV) infections. This study explores the relevance of this unique model regarding hepatitis/schistosomiasis interactions.

Methods: Woodchucks (Marmota monax and Marmota marmota) were infected with: (a), S. mansoni; (b), WHV; or (c), both $S$. mansoni and WHV.

Results: Following the experimental parasitic infection of woodchucks, with or without WHV, schistosomiasis presented a peculiar and severe course in early infection, involving mostly the intestines. Subsequently, the intestinal and hepatic lesions underwent considerable modulation and the periovular granulomas decreased in size and number, while the parasitic infection tended to self-cure within the 9 months following infection. Nine woodchucks inoculated with the hepatitis virus alone presented with several degrees of acute and chronic hepatitis, with one of them dying of hepatocarcinoma 1 year after inoculation. Four woodchucks with concomitant viral and schistosome infections presented with a simple additive pattern of lesions, without any evidence of modification or aggravation of either one of the two infections. Similarly, no significant impact of schistosomiasis on WHV serum markers could be seen.

Conclusions: Schistosomiasis and viral hepatitis in woodchucks run parallel courses, with neither apparent special histological features derived from the association of the two conditions, nor modulation of WHV replication. Schistosomiasis itself, however, was observed to run a peculiar course in the woodchuck. The present data are important for consideration in further experiments exploring the interplay between schistosomiasis and viral hepatitis induced liver damage in this unique experimental host.

(C) 2001 European Association for the Study of the Liver. Published by Elsevier Science B.V. All rights reserved.

Keywords: Viral B hepatitis; Schistosomiasis mansoni; Woodchucks

\section{Introduction}

Patients with Manson's hepatosplenic schistosomiasis were claimed to be 7-10 times more susceptible to co-infection with the hepatitis B virus than healthy blood donors from the same geographic area or even patients with mild schistosome infection [1-3]. Patients presenting the hepatosplenic form of schistosomiasis associated with hepatitis B usually show persistent viremia and exhibit chronic active hepatitis on liver biopsy, sometimes with the clinical picture of so-called decompensated schistosomiasis, evolving to

Received 1 August 1999; received in revised form 31 May 2000; accepted 28 June 2000

* Corresponding author. Tel.: +55 71356 4320; fax: +55 713562155 .

E-mail address: zilton@cpqgm.fiocruz.br cirrhosis $[1,3,4]$. Similar findings were also observed with viral hepatitis C $[5,6]$. Conversely, other studies denied any special relationship between schistosomiasis and infections with hepatotropic viruses [7-9]. The subject has been thoroughly reviewed in an article that significantly bears the title: 'Hepatitis B and schistosomiasis: interaction or no interaction?' [10].

To clarify these controversial observations, an experimental model susceptible to both schistosomiasis and viral hepatitis would be helpful. The woodchuck (Marmota monax) is unique in this regard, since it is both susceptible to a B-virus-like hepatitis, the woodchuck hepatitis virus (WHV) [11-14] and Schistosoma mansoni [15-17]. However, aside from the information that woodchucks can be infected with $S$. mansoni, can form periovular granulo- 
Table 1

General characteristics of woodchuck (M. marmota and M. monax) experimental infection with $S$. mansoni cercariae

\begin{tabular}{lllll}
\hline Number & Species & Number of cercariae & Duration of infection (months) & Type of death \\
\hline A1 & M. marmota & $350+1000$ & 9 & Sacrificed \\
A2 & M. marmota & 1000 & 2 & Spontaneous \\
A3 & M. marmota & 700 & 2 & Spontaneous \\
W563 & M. monax & 500 & 2 & Sacrificed \\
W566 & M. monax & $500+500$ & 6 & Spontaneous \\
W539 & M. monax & $500+500$ & 1 & Spontaneous \\
W555 & M. monax & 500 & 1 & Sacrificed \\
\hline
\end{tabular}

mas in their tissues and can eliminate viable eggs in the stools, very little is known about the kinetics of the infection in this host. This is a crucial point, since prolonged parasitic infection would be required for comparison with the disease as seen in man, and to study its relationship to viral hepatitis.

The present investigation is primarily concerned with establishing the main pathological characteristics of schistosomiasis in woodchucks and, at the same time, to observe which are the differential changes in animals with or without concomitant chronic WHV infection. This study was, therefore, an attempt to investigate whether the woodchuck would be the appropriate experimental model to clarify the problem of schistosomiasis/viral hepatitis interaction.

\section{Materials and methods}

\subsection{Single infection with S. mansoni}

Four eastern woodchucks (M. monax) and three alpine woodchucks (Marmota marmota, [18]), males and females, with weights varying from 6.4 to $2.4 \mathrm{~kg}$, were submitted to infection by subcutaneous injection of approximately 500 recently eliminated $S$. mansoni cercariae of a Brazilian strain [19]. Some animals received a second inoculum 1 or 2 months following the first infection, the total number of cercariae reaching 6501350. The animals were tested for hepatitis virus infection and all were negative. Every M. marmota presented antiviral antibodies in their sera (anti-WHBs), but they were negative for the viral antigen. The animals were not manipulated during hibernation, although two of them died during that period. The animals either died or were sacrificed within the periods from 1 to 9 months following first infection. The details can be seen in Table 1 .

\subsection{Infection with WHV alone}

Nine clean $M$. monax were inoculated with a pool of sera from three animals proven to be carriers of WHV. Serial bleedings and percutaneous needle biopsies of the liver were performed before infection, and at monthly intervals thereafter to monitor liver changes and WHV markers [20].

\subsection{Double infection with $S$. mansoni and WHV}

Four M. monax were included in this group. Two were carriers of the WHV and were submitted to infection with $S$. mansoni cercariae. The other two were simultaneously infected with both the hepatitis virus and $S$. mansoni. Details appear in Table 2.

\subsection{Pathology}

After death or sacrifice, the woodchucks were autopsied. Following gross inspection of the cavities, the liver, spleen, lungs and intestines were examined. Fragments of these organs were fixed in $10 \%$ buffered formalin and embedded in paraffin. Five-micrometer thick sections were stained using the following methods: hematoxylin and eosin, sirius red for collagen, Gomori's silver impregnation for reticulum, orcein for elastic fibers, periodic-acid Schiff (PAS), with and without previous diastase treatment, and with Perl's technique for iron.

\subsection{WHV infection monitoring}

WHsAg was determined using a commercial kit (AUSRIA, Abbott Park, IL) taking advantage of the antigenic cross reactivity with HBV. Quantification of secreted viral DNA was achieved by dot-blot analysis with a P32-labeled genomic WHV probe, as previously reported [20,21].

DNA polymerase (DNAp) was determined according to the method of Hantz et al. [22].

\section{Results}

\subsection{Single schistosomal infection}

During early infection, that is, up to 2 months, the intestines were the main site of lesions caused by schistosomes. Two animals died after presenting severe bloody diarrhea.

The number of eggs and the intensity of the inflammatory

Table 2

Data on M. monax infected with both WHV and $S$. mansoni

\begin{tabular}{lllll}
\hline \multirow{2}{*}{ Number } & Parasitic infection pattern & S. mansoni & \multirow{2}{*}{ Death } \\
\cline { 3 - 4 } & & Inoculum (cercariae) & Duration (months) & Spontaneous \\
W565 & Superinfection of WHV carrier & 500 & 8 & Spontaneous \\
W562 & Superinfection of WHV carrier & 650 & 9 & Sacrificed \\
W535 & Co-infection with WHV & 650 & 2 & Sacrificed \\
W534 & Co-infection with WHV & 500 & 7 & \\
\hline
\end{tabular}


response that resulted were greater in the sections taken from the intestines than in those from the liver or lungs. Both large and small intestines were similarly involved and the lesions were diffusely distributed, but with irregular focal areas of more accentuated involvement. Accumulation of granulomas in the submucosal and subserosal coats sometimes formed small tumor masses or polyps that bulged on the surfaces. The submucosa, and to a lesser extent, the muscular coat, were thickened and partially destroyed by the numerous large periovular granulomas (Fig. 1). Venous thrombosis with focal hemorrhage, necrosis and formation of micro-abscesses were noted. Inflammatory and fibrotic lesions around eggs were also seen within the subserosa and sometimes extended and involved the mesenteric adipose tissue. The granulomas were rich in macrophages. These cells were concentrically distributed around the parasite eggs, together with numerous eosinophils and some lymphocytes and fibroblasts. Central purulent necrosis was seen in a few granulomas, but a hyaline halo (Hoeppli phenomenon) was rarely seen. Surprisingly, fibrosis was not a prominent finding during the acute phase. The amount of collagen in the granulomas, as observed with picrosiriusred staining under polarized light, was usually scanty, rarely reaching a moderate degree, although a fair amount was seen in more chronic infections. The mucosa appeared preserved and contained a few mature eggs, usually without inflammatory reaction.

In the liver, periovular granulomas were scattered and distributed within the smaller portal spaces. They were isolated, rarely clustered, and were characterized in the acute phase by a predominantly exudative reaction around the mature eggs and, sometimes, by a large amount of periovular fibrosis, which expanded the fibrous tissue of a given portal space, but without causing systematized periportal fibrosis. A mild degree of septal fibrosis was noted radiating from fibrotic portal spaces. The portal cellular infiltration by mononuclear cells admixed with eosinophils was frequently seen, the intensity varying from mild to moderate. Some-

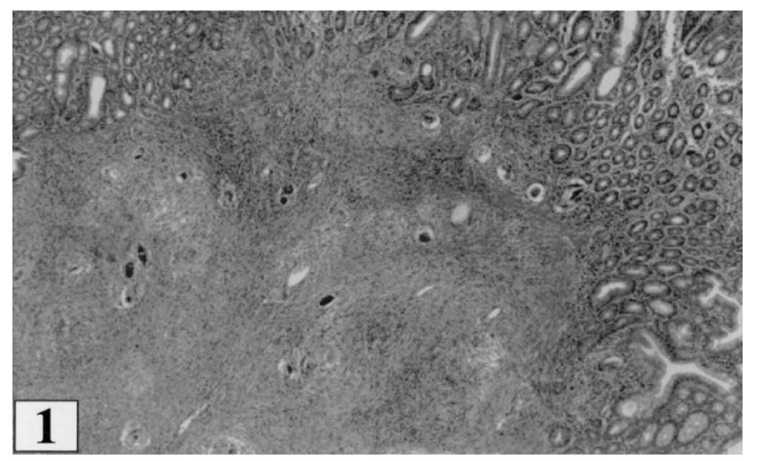

Fig. 1. Acute schistosomiasis in the woodchuck. Section of the large intestine showing several periovular granulomas in the submucosa of the small intestine. Numerous large schistosomal periovular granulomas are also seen dissociating and destroying the muscular layer. Hematoxylin and eosin; $\times 100$. times, these changes were seen regardless of the presence of granulomas, but did not involve all portal spaces. The liver parenchyma appeared undisturbed, even in the presence of many granulomas located within the portal spaces. The only parenchymal change was the vacuolization of hepatocytes (fatty change) which was sometimes massive. This change was probably related to hibernation and did not interfere with the number, type or size of periovular granulomas, nor with extra-granulomatous inflammatory reaction in periportal regions.

Considerable modulation of the lesions was present during chronic infection, both in the intestines and liver. In animals with 9-month-old infections, changes in these organs coincided with evident diminution of the parasitic elements. The eggs became scanty, being represented by a moderate number of calcified (dark) eggs and empty and fragmented shells were surrounded by small, pigmented, fibrotic granulomas (Fig. 2). Sometimes, numerous microscopic fields had to be searched to find one or a few periovular granulomas. However, the liver presented a mild to moderate fibrous expansion of the portal spaces, chronic hepatitis and a mild degree of septal fibrosis in the absence of obstructive or other portal vein lesions (Fig. 3).

Changes in the spleen and lungs were mostly non-specific. Congestion was marked during the acute changes, with considerable cellular hyperplasia in both the white and red pulps of the spleen. Later, the structure of the spleen returned to normal. The lungs sometimes presented a combination of acute congestion, focal broncho-pneumonia and interstitial pneumonitis, probably the immediate cause of death in some animals. No significant differences in the course of schistosomiasis and the type of associated lesions were seen between the two species of woodchucks studied.

\subsection{Single hepatitis virus infection}

From 1 to 2 months after inoculation, all animals in this group showed the classical features of acute viral hepatitis, with the presence of both WHsAg and WHV DNA in the serum. Needle biopsies performed early on during infection

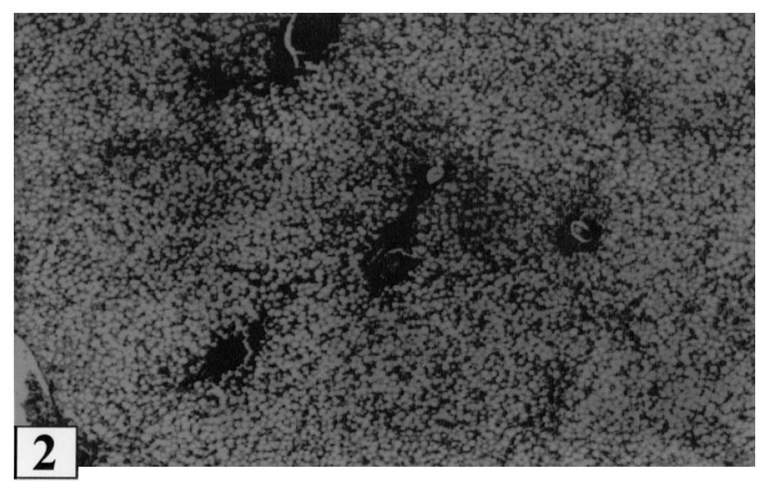

Fig. 2. At 6 months of infection the majority of the granulomas in the liver have a cicatricial appearance, with dense fibrous tissue encircling a still preserved egg. Hematoxylin and eosin; $\times 130$. 


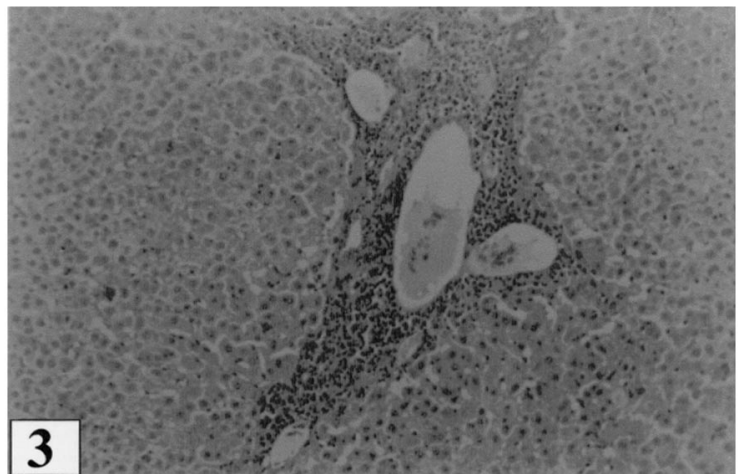

Fig. 3. Two-month-old schistosomal infection in M. marmota, in the absence of WHV infection. Features of chronic hepatitis are present in an expanded portal space. Although absent in this picture, granulomas were present in other areas of this liver. Similar findings were seen in other woodchucks with concomitant viral and schistosomal infections or with viral infection alone. Hematoxylin and eosin; $\times 120$.

revealed parenchymal disarray with diffuse leukocyte infiltration and hepatocyte ballooning. Six animals seroconverted to anti-WHsAg, became WHV-DNA negative, and resolved the acute hepatitis. Three other animals remained positive for hepatitis markers, developing a carrier state for WHV. Six months later, these three animals exhibited mild to moderate degrees of chronic hepatitis on liver biopsies, without fibrosis. The same histological features persisted thereafter, except in one animal which died and disclosed hepatocarcinoma at autopsy.

The most common hepatic changes were portal infiltration by mononuclear leukocytes. Some degree of small bile duct and ductular proliferation and mild fibrous expansion of the portal space were also present. Parenchymal changes were limited to focal steatosis and leukocyte accumulation in occasional sites of single cell necrosis.

\subsection{Schistosomiasis and viral hepatitis co-infection}

The changes observed in four animals with both schistosome and viral hepatitis infections presented a combination of the changes described in the two previous groups. Except for the presence of periovular granulomas and a more prominent degree of portal fibrosis, hepatic changes in this group did not differ from the previous ones. No difference was seen in the two carriers of WHV superinfected with schistosomiasis compared with the two others that were simultaneously co-infected with WHV and schistosomiasis. Chronic portal inflammation and mild parenchymal changes were equally present in the three groups. Portal and septal hepatitis were always mild to moderate. An admixture of lymphocytes with eosinophils was almost always present in the perigranulomatous infiltrates (Fig. 4). No signs of necro-inflammatory activity ('piece-meal necrosis') were seen.

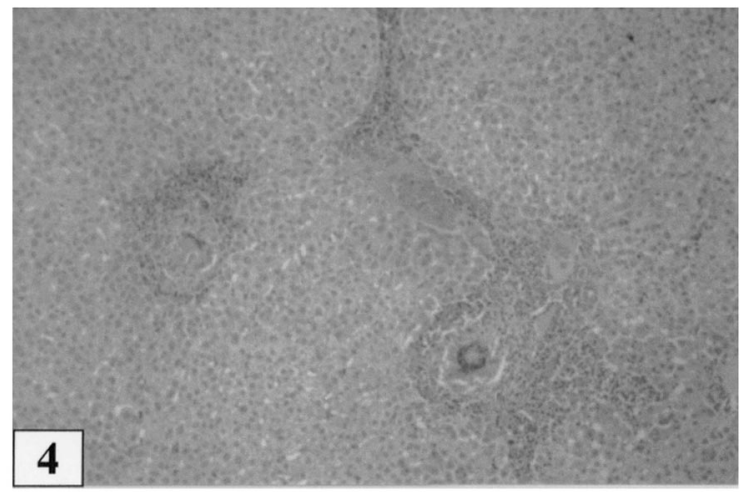

Fig. 4. Late hepatic schistosomiasis in a woodchuck that was also infected with the WHV. Mild infiltration of mononuclear cells at the periphery of periovular granulomas and in their proximity. Similar perigranulomatous inflammatory changes were also observed in the absence of WHV infection. Hematoxylin and eosin; $\times 120$.

\subsection{Impact of schistosomiasis on WHV markers}

Superinfection with S. mansoni in two WHV carriers did not significantly influence the serum levels of WHsAg, WHV DNA and DNAp in the two animals concerned (Fig. 5A,B). Similarly, neither the time course of WHsAg and WHV DNA nor their serum levels in the woodchucks

Detection of W Hs Ag in serum
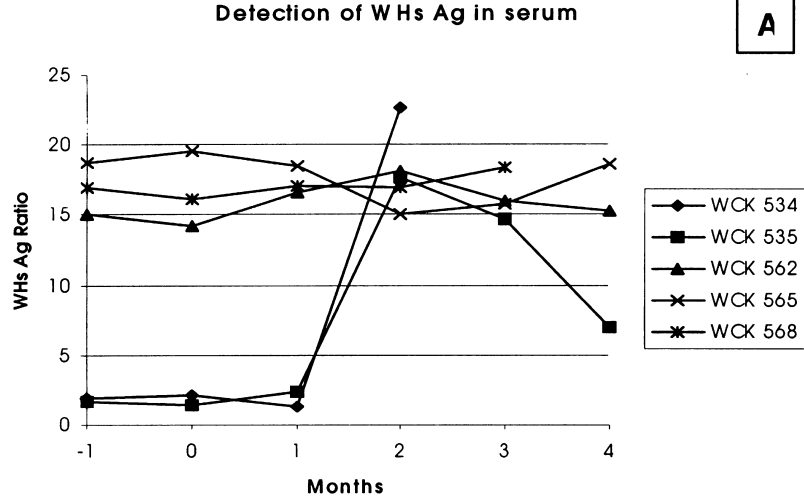

Defection of WHV DNA in serum

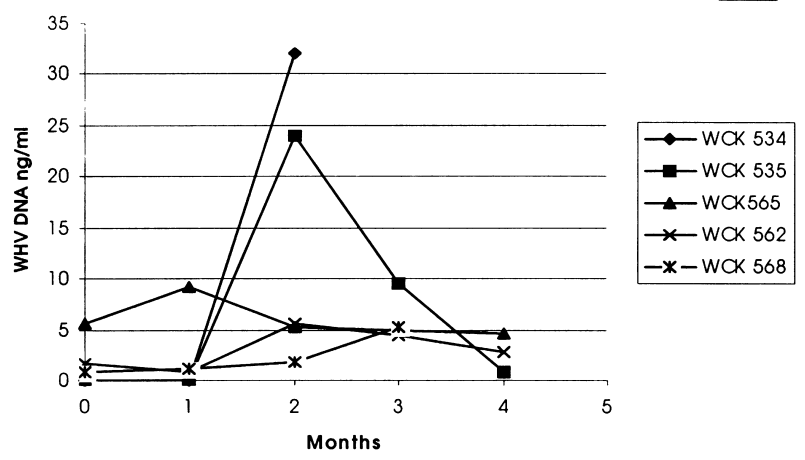

Fig. 5. Impact of schistosomiasis on WHV markers: (A), detection of WHsAg in serum; (B), detection of WHV DNA in serum. 
simultaneously co-infected with both agents differed from what was observed for the nine woodchucks inoculated with WHV alone (data not shown).

\section{Discussion}

Previous studies related to schistosomiasis affecting wild animals have indicated a susceptibility of $M$. monax to $S$. mansoni $[15,16]$. This rodent was found to be very susceptible to infection with $S$. mansoni and able to form large periovular granulomas in the liver, intestines and lungs in early infection. A third study, solely concerned with schistosomiasis in woodchucks, confirmed the previous reports [17]. The present study confirms the susceptibility of $M$. monax, and describes for the first time that M. marmota, the Alpine woodchuck, also presents a similar susceptibility. Unfortunately, M. marmota is not susceptible to the WHV [18]. Both species exhibited a similar and very peculiar behavior when infected with $S$. mansoni, the infection presenting a biphasic course. At first, the animals tended to develop an acute phase, with most of the lesions concentrated in the intestines, rather than in the liver, with large and destructive periovular granulomas. This involvement was so severe as to cause death. However, these intestinal and hepatic lesions were not only modulated with time, but the infection itself tended to undergo a self-cure within a span of 9 months. This peculiar feature limits the usefulness of the adult woodchuck schistosomal model, especially when the aim is to study its relationship to a long standing condition, such as viral hepatitis.

Mild to moderate degrees of chronic hepatitis were observed in the woodchucks with schistosomiasis, regardless of the presence of viral infection. Similar hepatitic changes have been seen in several other hosts with experimental schistosomiasis, and in the absence of viral hepatitis [23]. In this study, no specific interaction of the parasitic infection on WHV infection parameters could be seen. However, it could be argued that a prolonged time of observation would be necessary to follow the interplay with hepatitis. Most of the experimentally infected adult woodchucks experience self-limited hepatitis infection, while only the very young develop a chronic carrier state with a later phase of breakdown of immune tolerance and hepatitis exacerbation mimicking the natural history of HBV infection in man [11]. Further studies should therefore be carried out in younger woodchucks with a mild worm burden. Repeated cercarial expositions could also be tried in order to optimize the model. However, by comparison with what happens in other hosts, such as monkeys and rabbits [24-26], which are also able to control acute lesions and self-cure the infection, a strong and likely sterile immunity will develop and prevent further schistosome infections. Although the state of hibernation may also play a role in schistosomal infection, Hommel et al. [27] were unable to observe any modification in the course of $S$. mansoni infection in the golden hamster
(Cricetus cricetus) during hibernation. Despite its limitations, the woodchuck still remains the best candidate to experimentally explore the interrelationship between viral hepatitis B and schistosomiasis, an association affecting large population groups in tropical areas.

\section{References}

[1] Lyra LG, Rebouças G, Andrade ZA. Hepatitis B surface antigen carrier state in hepatosplenic schistosomiasis. Gastroenterology 1976;71:641-645.

[2] Guimarães RX, da Silva EC, Nigro SP, Kimura RT, Takeda A, Almeida FM. Sistemas antigênicos da hepatite B na esquistossomose mansônica. Arq Gastroenterol 1981;18:145-151.

[3] Daneshmend TK, Homeida H, Satir AA, Vandervelde EM. Increased hepatitis B infection in hepatosplenic schistosomiasis in the Sudan. East Afr Med J 1984;61:133-135.

[4] Ghaffar YA, Fattah SA, Kamel M, Badr RM, Mahomed FE, Strickland T. The impact of endemic schistosomiasis on acute viral hepatitis. Am J Trop Med Hyg 1991;45:743-750.

[5] Uemura K, Kawaguchi T, Sodeyama T, Kiyosawa K. Antibody to hepatitis $\mathrm{C}$ virus in patients with chronic schistosomiasis. Ann Trop Med Parasitol 1992;86:257-262.

[6] Pereira LMMB, Melo MCV, Saleh MG, Koskinas J, Domingues ALC, Soinelli V, et al. Hepatitis C virus infection in schistosomiasis mansoni in Brazil. J Med Virol 1995;45:423-428.

[7] Domingo EO, Lingao AL, Tiu E, Lao JY, Olveda RM. HBV exposure and HBsAg positivity rates in schistosomiasis japonica: study in a Philippine community endemic for both infections. Southeast Asian J Trop Med Public Hlth 1983;14:456-462.

[8] Eltoum IA, Gahlib HW, Gadir AFA, Suliaman SM, Homeida MMA. Lack of association between schistosomiasis and hepatitis B virus infection in Gezira-Managil area, Sudan. Trans R Soc Trop Med Hyg 1991;85:81-82.

[9] Larouzé B, Sazza MC, Guadebout C. Absence of relationship between Schistosoma mansoni and hepatitis B virus infection in the Qalyub Governate, Egypt. Ann Trop Med Parasitol 1987;81:373-375.

[10] Chen MG, Mott KE, Wang Q, Kane M. Hepatitis B and schistosomiasis: interaction or no interaction. Trop Dis Bull 1993;90:97-115.

[11] Frommel D, Crevat D, Vitvitski L, Pichoud C, Hantz O, Chevalier M, et al. Immunopathologic aspects of woodchuck hepatitis. Am J Pathol 1984;115:125-134.

[12] Möröy T, Marchio A, Etiemble J, Trepo C, Tiollais P, Buendia MA. Rearrangement and enhanced expression of c-myc in hepatocellular carcinoma of hepatitis virus infected woodchucks. Nature 1986;324:276-279.

[13] Popper H, Roth L, Purcell RH, Tennant BC, Gerin JL. Hepatocarcinogenicity of the woodchuck hepatitis virus. Proc Natl Acad Sci USA 1987;84:866-870.

[14] Abe K, Kurata T, Shikata T, Tennant BC. Enzyme-altered liver cell foci in woodchucks infected with woodchuck hepatitis virus. Jpn J Cancer Res 1988;79:466-473.

[15] Bruce JI, Llewellyn LM, Sadun EH. Susceptibility of wild mammals to infection by Schistosoma mansoni. J Parasitol 1961;47:752-756.

[16] Lichtenberg FV, Sadun EH, Bruce JI. Tissue responses and mechanisms of resistance in schistosomiasis mansoni in abnormal hosts. Am J Trop Med Hyg 1962;11:347-356.

[17] Anderson WI, King JM, Uhl EM, Hornbuckle WE, Tennant C. Pathology of experimental Schistosoma mansoni infection in the eastern woodchuck (Marmota monax). Vet Pathol 1991;28:245-247.

[18] Chomel B, Trepo C, Pichoud C, Jacquet C, Boulay J, Joubert L. Infection spontanée et expérimentale de la marmotte alpine (Marmota marmota) par le virus de l'hépatite de la marmotte nord-américaine (Marmota monax), premiers résultats. Comp Immunol Microbiol Infect Dis 1984;7:179-194. 
[19] Andrade ZA, Sadigursky M. Um estudo comparativo das cepas Feira de Santana (Bahia) e Porto Rico do Schistosoma mansoni na infecção experimental do camundongo. Mem Inst Oswaldo Cruz 1985;80:3740.

[20] Paraná R, Gerard JL, Lesbordes C, Pichoud L, Vitvitski LG, Lyra C, et al. Serial transmission of spongiocytic hepatitis to woodchucks. J Hepatol 1995;22:41-47.

[21] Scotto J, Hadchovel M, Hery C, Yvart J, Tiollais P, Brechot C. Detection of hepatitis B virus DNA in serum by a single spot hybridization technique: comparison with results for other viral markers. Hepatology 1983;3:279-283.

[22] Hantz O, Fourel I, Buendia B, Baginski I, Trepo C. Specificity of the woodchuck hepatitis virus associated protein kinase. In: Zuckerman A, editor. Viral hepatitis and liver disease, New York: Alan R. Liss, 1988. pp. 471-476.
[23] Andrade ZA, Cheever AW. Chronic hepatitis in experimental schistosomiasis. Virchows Arch 1995;426:87-93.

[24] Lindberg J, Pichoud C, Hantz O, Vitvitski L, Grimaud JA, Gilbert JM, et al. Woodchuck hepatitis virus infection: serologic and histopathologic course and outcome. Eur J Clin Microbiol 1985;4:59-61.

[25] Andrade ZA, Ramos E, Reis MG. A patologia da esquistossomose mansoni no coelho. Mem Inst Oswaldo Cruz 1988;83:323-332.

[26] Warren KS, Jane JA. Comparative susceptibility to Schistosoma mansoni of the squirrel monkey, the slow loris and the tree shrew. Trans R Soc Trop Med Hyg 1967;61:534-537.

[27] Hommel M, Miltgen F, Ganguilhem B. Le hamster d'Europe (Cricetus cricetus) hôte. Expérimental nouveau de Schistosoma mansoni. Étude des effets de l'hibernation. Bull Soc Pathol Exot 1973;66:296298. 